\title{
Effect of mesoionic 4-phenyl-5-(cinnamoyl)-1,3,4- thiadiazolium-2-phenylamine chloride derivative salts on the activities of the nitric oxide synthase and arginase of Leishmania amazonensis
}

Rômulo José Soares-Bezerra, Edson F. da Silva, Aurea Echevarria, Liliane Gomes-da-Silva, Léa Cysne-Finkelstein, Fabiane Pereira Monteiro, Leonor L. Leon \& Marcelo Genestra

To cite this article: Rômulo José Soares-Bezerra, Edson F. da Silva, Aurea Echevarria, Liliane Gomes-da-Silva, Léa Cysne-Finkelstein, Fabiane Pereira Monteiro, Leonor L. Leon \& Marcelo Genestra (2008) Effect of mesoionic 4-phenyl-5-(cinnamoyl)-1,3,4-thiadiazolium-2-phenylamine chloride derivative salts on the activities of the nitric oxide synthase and arginase of Leishmania amazonensis, Journal of Enzyme Inhibition and Medicinal Chemistry, 23:3, 328-333, DOI: $10.1080 / 14756360701585619$

To link to this article: https://doi.org/10.1080/14756360701585619

\section{曲 Published online: 04 Oct 2008.}

Submit your article to this journal

Џll Article views: 112

Citing articles: 4 View citing articles 


\title{
Effect of mesoionic 4-phenyl-5-(cinnamoyl)-1,3,4-thiadiazolium-2- phenylamine chloride derivative salts on the activities of the nitric oxide synthase and arginase of Leishmania amazonensis
}

\author{
RÔMULO JOSÉ SOARES-BEZERRA ${ }^{1}$, EDSON F. DA SILVA ${ }^{2}$, AUREA ECHEVARRIA $^{2}$, \\ LILIANE GOMES-DA-SILVA ${ }^{1}$, LÉA CYSNE-FINKELSTEIN ${ }^{1}$, FABIANE PEREIRA \\ MONTEIRO $^{1}$, LEONOR L. LEON ${ }^{1}$, \& MARCELO GENESTRA ${ }^{1}$ \\ ${ }^{1}$ Department of Immunology-Oswaldo Cruz Institute, Oswaldo Cruz Foundation-FIOCRUZ, Rio de Faneiro, Brazil, and \\ ${ }^{2}$ Department of Chemistry-Federal Rural University of Rio de Faneiro, Rio de Faneiro, Brazil
}

(Received 5 Fanuary 2007; in final form 14 fune 2007)

\begin{abstract}
L-arginine is involved in the production of both nitric oxide (NO), mediated by nitric oxide synthase (NOS) and L-ornithine, by arginase activity. It is generally accepted that NO regulation occurs mainly at the transcriptional level of NOS. In a previous work we purported that there is evidence that Leishmania sp. can produce NO from L-arginine. An arginase activity in its gene sequence has also been reported in Leishmania parasites. In a search for intracellular targets as potential antileishmanicidal agents, such as the L-arginine metabolism, we used 1,3,4-thiadiazolium mesoionic compounds, that have been demonstrated to be cytotoxic to the Leishmania amazonensis, when compared to Pentamidine isethionate as a reference drug. Parasites were assayed in absence/presence of $4^{\prime}$ - and $3^{\prime}$ - methoxy mesoionic derivatives in order to verify the effect on NO production and arginase activity in L. amazonensis. The results indicated that the drugs reduce from 70 to $90 \%$ of the NO production by the parasite and act on a soluble nitric oxide synthase purified from L. amazonensis promastigotes and axenic amastigotes.
\end{abstract}

Keywords: Leishmania amazonensis, mesionic compounds, phenyl-5-(cinnamoyl)-1,3,4-thiadiazolium-2-phenylamine, nitric oxide, nitric oxide synthase, arginase

\section{Introduction}

Leishmania parasites are small and intriguing organisms that cause Leishmaniasis (cutaneous, mucocutaneous and visceral) in tropical and subtropical regions of 88 countries [1]. Thus, more efforts have been concentrated on the further identification of constituent intracellular molecules and the possible antileishmanicidal drug targets. Arginase hydrolyzes Larginine into L-ornithine and urea. L-ornithine favors parasite growth and it is a precursor for the synthesis of L-glutamine, L-proline and polyamines via the ornithine decarboxylase (ODC) pathway. Polyamines have multiple roles in stabilizing nucleic acid and membranes, as well as regulating cell growth and differentiation $[1,2]$.
Recent results from our laboratory reported NO production by Leishmania sp. and the participation of the NO-L. amazonensis pathway in the host/parasite interaction [3-5]. Although the macrophages triggered their defense mechanism to neutralize the parasite, there are evidences that the NO pathway from $L$. amazonensis participates in the parasite-host interaction, and there is a correlation between NO production and the amount of metacyclic forms in the culture of infective forms [4-6]. Additionally, recent results also demonstrated that $L$. amazonensis axenic amastigotes produce NO [7], as well as the fact that the NOS activity is evident in this evolutive form, suggesting that both the NOS pathway and the arginase are cross talking during the signaling involving host cell-parasite interaction [3-8].

Correspondence: M. Genestra, Department of Immunology-Oswaldo Cruz Institute, Oswaldo Cruz Foundation-FIOCRUZ, Rio de Janeiro, Brazil. Fax: 55212290 0479. E-mail: genestra@ioc.fiocruz.br 
Arginase is a binuclear manganese metalloenzyme that catalyses the hydrolysis of L-arginine into Lornithine and urea, and this activity has been implicated in the regulation of the NO synthesis, modulation of the availability of L-arginine and consequently being linked to the cytotoxic processes in immunological mechanisms of protection against infectious diseases $[9,10]$. The activity of arginase in parasitic protozoa of the Trypanosomatidae family was shown to be genus specific and has been used as an identification and classification tool. Leishmania is one genus in that family in which arginase activity is detectable and is considered to play a role in ornithine production [10].

The identification of parasite factors that induce arginase, as well as the membrane receptors and signaling involved, will make it possible to target the best way to inhibit the modulation NOS/arginase pathway. Thus, arginase inhibition could be useful in some tissues, in which NO production is required, but should be avoided in other tissues, where NO production has to be down regulated. Moreover, a great care must be taken to avoid blocking host urea formation. Therefore, besides the use of arginase inhibitors, the modulation of arginase transcription could represent a new field of investigation [11].

As a part of our research program on experimental chemotherapy against Leishmaniasis, we decided to evaluate the effect of two salts of mesoionic derivatives on the NOS/arginase pathways of the parasite. Mesoionic salts have provided numerous compounds with antifungal, antibacterial and antitumor (against Ehrlich carcinoma and Sarcoma) activities [12,13]. These compounds possess structural features, which have been of considerable interest to medicinal chemistry. They are characterized as containing a five or six-membered heterocyclic aromatic ring that has a partial positive charge which is balanced by a corresponding negative charge on an exocyclic atom or group and must be planar or nearly so as well as possessing considerable resonance energy. Their potential value as biologically active substances is found in the planar aromatic character (Figure 1). The association of these characteristics with the little polyhetero-atomic system suggests a high probability of strong interactions with the biomolecules, such as proteins [13]. In contrast with sydnones, sydnonimines and oxatriazol (Figure 2a, 2b, 2c), 4-phenyl-5(cinnamoyl)-1,3,4-thiadiazolium mesoionic derivative salts are not NO donors (Figure 2d).

\section{Materials and methods}

\section{Reagents}

Benzamidine, trypsin inhibitor, penicillin $\mathrm{G}, \mathrm{KCl}$, leupeptin, L-glutamine, Schneider's Insect Medium, $\mathrm{MgCl}_{2}$, phenylmethylsulfonyl fluoride (PMSF),

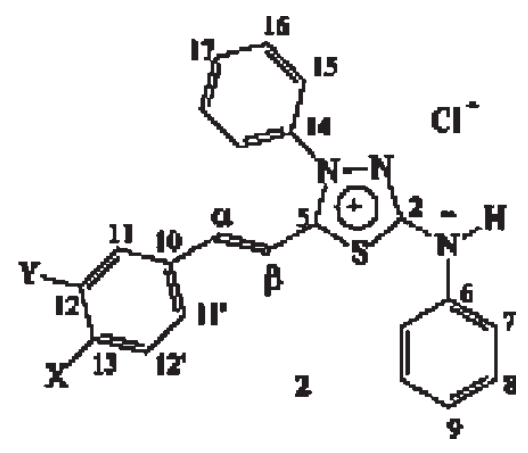

Figure 1. Chemical structure of the mesoionic salt derivatives, 4phenyl-5-(3'-Y- or 4'-X-cinnamoyl)-1,3,4-thiadiazolium-2phenylamine chlorides. The numeration of structure is only for chemical shifts attribution.

N-1-naphtylethylenediamine, phosphoric acid, polyethyleneglycol, sulfanilamide, sucrose, Tris- $\mathrm{HCl}$, dithiotreitol (DTT), aprotinin, L-arginine, $\mathrm{NADH}$, NADP, NADPH, EGTA-AM (acethoxy methyl ethylene glycol-bis [ $\beta$-aminoethyl ether]-N, $, N^{\prime}, N^{\prime}-$ tetra acetic acid), L-NAME ( $\mathrm{N}^{\omega}$-nitro-L-arginine methyl esther), (6R)-5,6,7,8-tetrahydrobiopterin $\left(\mathrm{H}_{4} \mathrm{~B}\right), 2^{\prime}-5^{\prime}-\mathrm{ADP}$ agarose, RPMI and rabbit IgGanti nNOS (N7280/rat brain origin) were from Sigma Chemical Co., St. Louis, MO (USA). Glycerol, fluorescein isothiocyanate and formaldehyde were from Bio Rad (USA). Fetal calf serum (FCS) was from Gibco BRL (USA). Electrophoresis was performed using Phast-System (Pharmacia LKB Biotechnology Inc.).

\section{Parasites}

Leishmania amazonensis (MHOM/BR/77/LTB0016 strain), infective promastigotes (IP) and axenic amastigotes (AA) were studied comparatively. IP $\left(4^{\text {th }}\right.$ passage) had a high percentage $(\sim 73 \%)$ of metacyclic forms, evaluated through complement lysis test. Promastigotes were maintained in Schneider's Insect
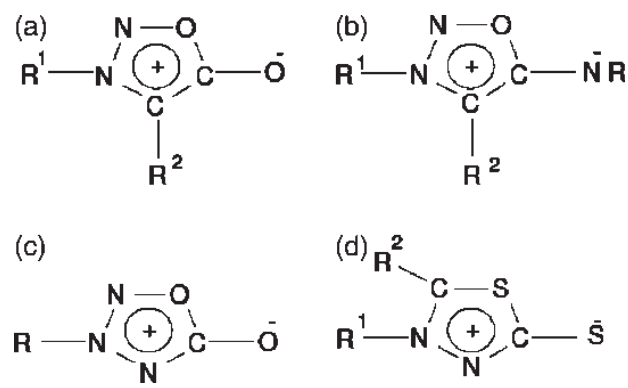

Figure 2. Mesoionic compounds (sydnone and thiadiazolium). $2 \mathrm{a}=$ sydnones $(1,2,3$-oxadiazolium-5-olate $) ; 2 \mathrm{~b}=$ sydnonimines (1,2,3-oxadiazolium-5-aminide); $2 \mathrm{c}=$ oxatriazoles $\quad(1,2,3,4$ oxatriazoles-5-olate); $2 \mathrm{~d}=1,3,4$ - thiadiazolium mesoionic $(1,3,4$ thiadiazolium-2-thiolate). 
Medium supplemented with $10 \%$ of heat inactivated FCS at $26^{\circ} \mathrm{C}$ and $\mathrm{pH}$ 7.2.AA were also cultivated in the same medium, but with $20 \% \mathrm{FCS}$ at $32^{\circ} \mathrm{C}$ and pH 5.5 [15].

\section{Drug test}

Both developmental stages of $L$. amazonensis were added with the corresponding $\mathrm{LD}_{50} / 24 \mathrm{~h}$ of mesoionic salts (test compounds) and pentamidine isethionate (reference drug substance $/ \mathrm{LD}_{50}=0.46 \mu \mathrm{M}$ for promastigotes and $118 \mu \mathrm{M}$ for amastigotes) [16]. 1,3,4,-thiadiazolium mesoionic compounds were obtained from the Department of Chemistry, Federal Rural University of Rio de Janeiro (UFRRJ). The more active mesoionic compounds were tested: 4-phenyl-5-(4'-R- or 3'-R-cinnamoyl)-1,3,4-thiadiazolium-2-phenylamine chlorides, were $R=$ methoxy, in the following concentrations: $1.7 \mathrm{mM}$ and $2.4 \mathrm{mM}$, for promastigotes and $167.7 \mathrm{mM}$ and $120.8 \mathrm{mM}$ for amastigotes, respectively. Infective promastigotes and axenic amastigotes $\left(4 \times 10^{6}\right)$ were cultured in absence/presence of the compounds. The mesoionic compounds were added to parasite cultures solubilized in DMSO (the highest concentration used was $1.6 \%) \mathrm{v} / \mathrm{v}$, not hazardous to the parasites) [16].

\section{Nitrite determination}

After $24 \mathrm{~h}$ of culture, parasites were counted in a Neubauer's chamber centrifuged at $1,500 \mathrm{~g}$ for $10 \mathrm{~min}$ and the supernatants were collected. Nitrite, a stable oxidation product of $\mathrm{NO}$, was measured spectrophotometricaly by adding Griess reagent $(0.1 \% \mathrm{~N}-1-$ naphtylethylenediamine in 5\% phosphoric acid and $1 \%$ sulfanilamide) to the same volume of parasite (IP/AA) culture supernatants. After $10-15 \mathrm{~min}$ at room temperature, the absorbance of the chromophore was measured at $540 \mathrm{~nm}$ (JEWAY 6405 Spectrophotometer, England). Nitrite concentrations were estimated by comparison with a standard curve prepared with sodium nitrite in Schneider's medium with FBS $[4,6,12,17]$.

Isolation of NOS from $\mathrm{L}$. amazonensis promastigotes and axenic amastigotes

The purification protocol of NOS was the same used by Basu et al. [18], with some modifications, as follows: cell-free extract was prepared from IP and from AA by freeze-thawing the cell suspension $\left(5 \times 10^{9}\right.$ cells $\left.\mathrm{mL}^{-1}\right) 3-5$ times and sonicating $5 \times 45 \mathrm{~s}$ over ice in $0.25 \mathrm{~mol} / \mathrm{L}$ sucrose containing $5 \mathrm{mM} \mathrm{KCl}$. The contents were centrifuged at $10,000 \times \mathrm{g}$ for $30 \mathrm{~min}$ and the supernatant was adjusted to antiproteolytic buffer containing $0.1 \mathrm{mM}$ PMSF (phenylmethylsulfonyl fluoride), $0.01 \%(\mathrm{p} / \mathrm{v})$ leupeptin, $0.2 \mathrm{mg} / \mathrm{mL}$ trypsin inhibitor and $1 \mathrm{mM}$ benzamidine to a final volume of $5 \mathrm{~mL}$. The crude soluble extract was centrifuged at $100,000 \times \mathrm{g}$ for $60 \mathrm{~min}$ at $4^{\circ} \mathrm{C}$ and the supernatant $(1.3 \mathrm{mg} / \mathrm{mL}$ protein) was applied to a column $(8.5 \times 1.5 \mathrm{~cm})$ packed with $2^{\prime}, 5^{\prime}-$ ADP agarose equilibrated with $10 \mathrm{mM}$ Tris- $\mathrm{HCl}, \mathrm{pH} 7.5$ containing $1 \mathrm{mM}$ DTT (dithiotreitol), $1 \mathrm{mM}$ EDTA, $0.5 \mathrm{mM}$ PMSF, 25 units $/ \mathrm{mL}$ aprotinin and $0.5 \mathrm{mM} \mathrm{L}$-arginine (buffer A). The column was then washed successively with $20 \mathrm{~mL}$ of buffer A, $20 \mathrm{~mL}$ of buffer A containing $0.5 \mathrm{mM} \mathrm{NADH}, 20 \mathrm{~mL}$ of buffer A contaning $0.5 \mathrm{mM}$ NADP and $20 \mathrm{~mL}$ of buffer $\mathrm{A}$. The enzyme was eluted with $10 \mathrm{~mL}$ of buffer A containing $10 \mathrm{mM} \mathrm{NADPH}$, $3 \mu \mathrm{M} \mathrm{H}_{4} \mathrm{~B}$ and $10 \%(\mathrm{v} / \mathrm{v})$ glycerol and concentrated to $2 \mathrm{~mL}$ using a cellulose semipermeable membrane/ polyethyleneglycol 400 (PEG 400) system. The protein concentration $(240 \mu \mathrm{g} / \mathrm{mL})$ was estimated spectrophotometricaly $(260-280 \mathrm{~nm})$ and the sample was utilized to evaluate the pureness, through SDSPAGE [19].

\section{$S D S-P A G E$}

Electrophoresis (Polyacrylamide gel containing sodium dodecyl sulphate/ SDS-PAGE) was performed using Phast-System on a 10-15\% gel according to the manufacturer's directions. The gels were stained with silver nitrate. Molecular weight standards (Bio-Rad) were: myosin (200 kDa), $\beta$ galactosidase $(116.2 \mathrm{kDa})$, rabbit muscle phosphorylase $\mathrm{b}(97.4 \mathrm{kDa})$, bovine serum albumin $(66.2 \mathrm{kDa})$ and egg white ovoalbumin $(42.6 \mathrm{kDa})$.

\section{NOS-L. amazonensis activity}

The NOS activity purified from IP and AA was determined by measuring the reduction in the absorbance at $340 \mathrm{~nm}$ for $10 \mathrm{~min}$ continuously, once the NADPH was consumed during the conversion of L-arginine to L-citrulline by NOS [20]. Briefly, The complete enzyme reaction mixture contained $50 \mathrm{mM}$ potassium phosphate buffer $(\mathrm{pH} 7.4), 1 \mathrm{mM}$ $\mathrm{CaCl}_{2}, 0.1 \mathrm{mM} \mathrm{NADPH}, 80 \mu \mathrm{M} \mathrm{H}_{4} \mathrm{~B}, 10 \mu \mathrm{M}$ FAD, $10 \mu \mathrm{M}$ FMN, $0.1 \mathrm{mM}$ L-arginine and $2 \mu \mathrm{g}$ enzyme in a final volume of $1 \mathrm{~mL}$, at $25^{\circ} \mathrm{C}$. Alternatively, 4phenyl-5-( $3^{\prime}$ or $4^{\prime}$-methoxy-cinnamoyl)-1,3,4-thiadiazolium-2-phenylamine chlorides were used in the reaction mixture in the follows concentrations: $1.7 \mathrm{mM}$ and $2.4 \mathrm{mM}$, for promastigotes and $167.7 \mathrm{mM}$ and $120.8 \mathrm{mM}$ for amastigotes, respectively. Pentamidine isethionate was used in the reaction mixture as a drug control using the corresponding $\mathrm{LD}_{50}$ [16]. The control group had all the components of the reaction mixture, except the drugs, and the blank had all the components, except NADPH and the drugs $[6,19]$. 
Arginase-L. amazonensis activity

Arginase activity from L. amazonensis promastigotes and axenic amastigotes treated for $24 \mathrm{~h}$ with corresponding $\mathrm{LD}_{50}$ of 4-phenyl-5-(3' or $4^{\prime}$-methoxycinnamoyl)-1,3,4-thiadiazolium-2-phenylamine chlorides was verified as previously described [21], with some modifications. Briefly, $10^{6}$ cells previously washed with a solution of $0.25 \mathrm{M}$ sucrose and $5 \mathrm{mM}$ $\mathrm{KCl}$ were added to $0.5 \mathrm{~mL}$ of $0.1 \%$ Triton $\mathrm{X}-100$ in an antiproteolytic buffer containing $0.1 \mathrm{mM}$ phenylmethylsulfonyl fluoride, $0.01 \% \mathrm{w} / \mathrm{v}$ leupeptin, $0.2 \mathrm{mg} / \mathrm{mL}$ trypsin inhibitor and $1 \mathrm{mM}$ benzamidine in $0.25 \mathrm{M}$ sucrose and $5 \mathrm{mM} \mathrm{KCl}$. The mixture was then stirred for $30 \mathrm{~min}$ at room temperature. After the cells were lysed, $0.5 \mathrm{~mL}$ of $25 \mathrm{mM}$ Tris $-\mathrm{HCl}$ plus $5 \mathrm{mM}$ of $\mathrm{MnCl}_{2}, \mathrm{pH} 7.4$ were added and the enzyme was activated for $10 \mathrm{~min}$ at $56^{\circ} \mathrm{C}$. Arginine hydrolysis was initiated by the addition of $25 \mu \mathrm{L}$ of $0.5 \mathrm{M} \mathrm{L-}$ arginine, $\mathrm{pH} 9.7$ to a $25 \mu \mathrm{L}$ aliquot of the previously activated lysate. Incubation was performed at $37^{\circ} \mathrm{C}$ for $60 \mathrm{~min}$ and the reaction was stopped by the addition of $400 \mu \mathrm{L}$ of an acid mixture containing $\mathrm{H}_{2} \mathrm{SO}_{4}, \mathrm{H}_{3} \mathrm{PO}_{4}$, and $\mathrm{H}_{2} \mathrm{O}(1: 3: 7)$. The urea formed was colorimetricaly quantified at $540 \mathrm{~nm}$ after addition of $25 \mu \mathrm{L}$ of $9 \% \alpha-$ isonitrosopropienophenone (dissolved in $100 \%$ ethanol) and heating at $100^{\circ} \mathrm{C}$ for $45 \mathrm{~min}$. After $10 \mathrm{~min}$ in the dark, the optical density was determined in a spectrophotometer using $200 \mu \mathrm{L}$ aliquots in a nonsterile micro-culture plate. A calibration curve was prepared with increasing amounts of urea between 1.5 and $30 \mu \mathrm{g} / \mathrm{mL}$.

\section{Data analysis}

Three independent experiments were performed and the data obtained with different treatments was analyzed statistically using 1-way ANOVA and Students $t$-test $(\mathrm{p}<0.05)$ and expressed as the mean \pm standard deviation.

\section{Results and discussion}

The NO released by $L$. amazonensis IP (stationary phase) and AA was measured by the nitrite concentration in the culture supernatants, using Griess reagent. The results showed that 4-phenyl-5(3'- or 4'-methoxy-cinnamoyl)-1,3,4-thiadiazolium-2phenylamine chlorides reduce the NO production in IP cultures (Figure 3a). The reduction was of about $80 \% \quad\left(\mathrm{R}=3^{\prime}\right.$-methoxy-cinnamoyl, $\left.\mathrm{p}=0.002\right)$ and $70 \%\left(\mathrm{R}=4^{\prime}\right.$-methoxy-cinnamoyl, $\left.\mathrm{p}=0.0011\right)$. Pentamidine isethionate (reference drug) was able to inhibit only $2 \%$ of the NO production compared to control $(\mathrm{p}=1,45)$. When the assay was made using AA cultures, $3^{\prime}$-methoxy-cinnamoyl inhibited the NO production, showing the same profile observed in IP cultures $(\mathrm{p}=0.0034)$, but the $4^{\prime}$-methoxy-cinnamoyl
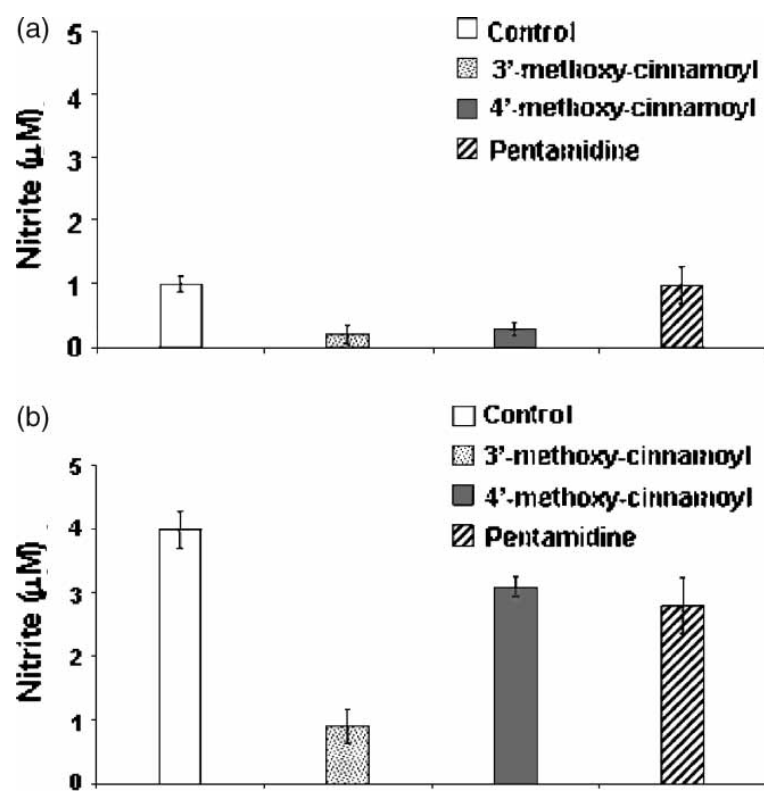

Figure 3. Comparative levels of NO released as nitrite in the supernatant of infective promastigotes/IP (a) and axenic amastigotes/AA (b) cultures of L. amazonensis in presence of 4phenyl-5-cinnamoyl-1,3,4-thiadiazolium-2-phenylamine chlorides (3'- or 4'-methoxy), where $3^{\prime}$ - was more active than $4^{\prime}$ compoundand Pentamidine isethionate in axenic amastigotes.

compound was less effective in AA (inhibition of $25 \%$, $\mathrm{p}=0.019$ ). In AA cultures, pentamidine isethionate inhibited the NO production by about $30 \%$ $(\mathrm{p}=0.03)$ (Figure 3b).

Since the NO production could be intervening directly or not with the activity of the NOS, it was verified that, after the NOS purification from IP

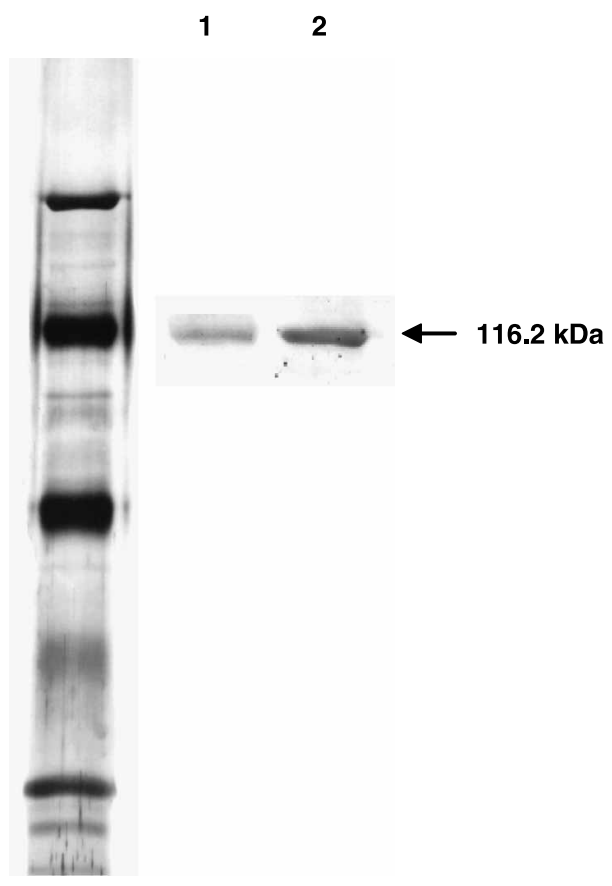

Figure 4. SDS-PAGE of NOS molecule purified from $L$. amazonensis promastigotes (line 1) and axenic amastigotes (line 2). 

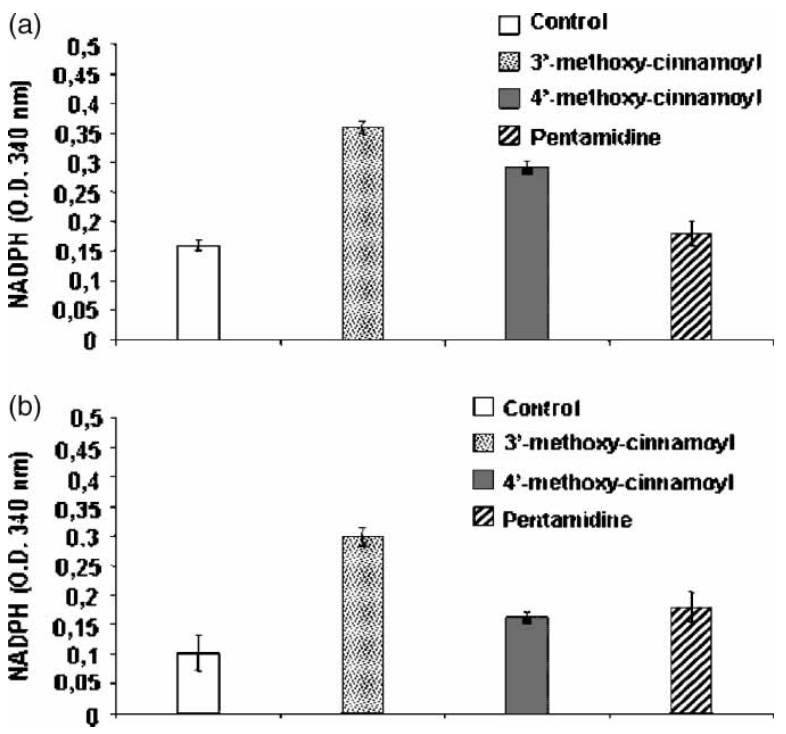

Figure 5. Evaluation of the activity of NOS purified from L. amazonensis promastigotes/IP (a) and axenic amastigotes/AA (b), according to the consumption of NADPH, in presence/absence of mesoionic compounds. Data represent mean \pm S.D. of three independent determinations.

(Figure 4/line 1) and AA (Figure 4/line2), through $2^{\prime}, 5^{\prime}$-ADP-agarose column, the activity assay of the enzyme, through NADPH consumption, showed that the mesoionic compounds act directly on purified enzymes (Figure 5). This data indicates the significant reduction in consumption from about 2.33 ( $3^{\prime}-$ methoxy $/ \mathrm{p}=0.003)$ to $1.9\left(4^{\prime}-\right.$ methoxy $\left./ \mathrm{p}=0.025\right)$ fold in NOS-purified from IP cultures (Figure $5 \mathrm{a}$ ) and in NOS-purified from AA, the reduction of the cofactor consumption was from about 2.9 (3'methoxy $/ \mathrm{p}=0.0025)$ to $1.6\left(4^{\prime}-\right.$ methoxy $\left./ \mathrm{p}=0.051\right)$ fold (Figure 5b) compared to the control (without drugs), while Pentamidine inhibited 1.8 fold $(\mathrm{p}=0.05)$.

The effect of $3^{\prime}$ or $4^{\prime}$-methoxy-cinnamoyl mesoionic salts on arginase activity is showed in Figure 6. There is no significant reduction of arginase activity in IP (Figure 6a), but in AA, 3'-methoxy-cinnamoyl significantly inhibited arginase activity and this reduction was about $30 \%(\mathrm{p}=0.003)$ (Figure $6 \mathrm{~b})$.

Mesoionic systems have provided numerous compounds with useful and wide-ranging biological activities. These compounds have well separated regions of positive and negative charges. This association with the polyhetero-atomic system suggested a high probability of strong interaction with biomolecules. Searching for intracellular targets of antiLeishmania drugs, we tested some mesoionic derivatives against NOS and arginase pathways of $L$. amazonensis, which seems to be important during the parasite-host cell interaction $[1,4,5,18,21,22]$.

NO synthesis has always been observed in mammals [23] and invertebrates [24], through NOS. The first demonstration of the existence of the NO pathway
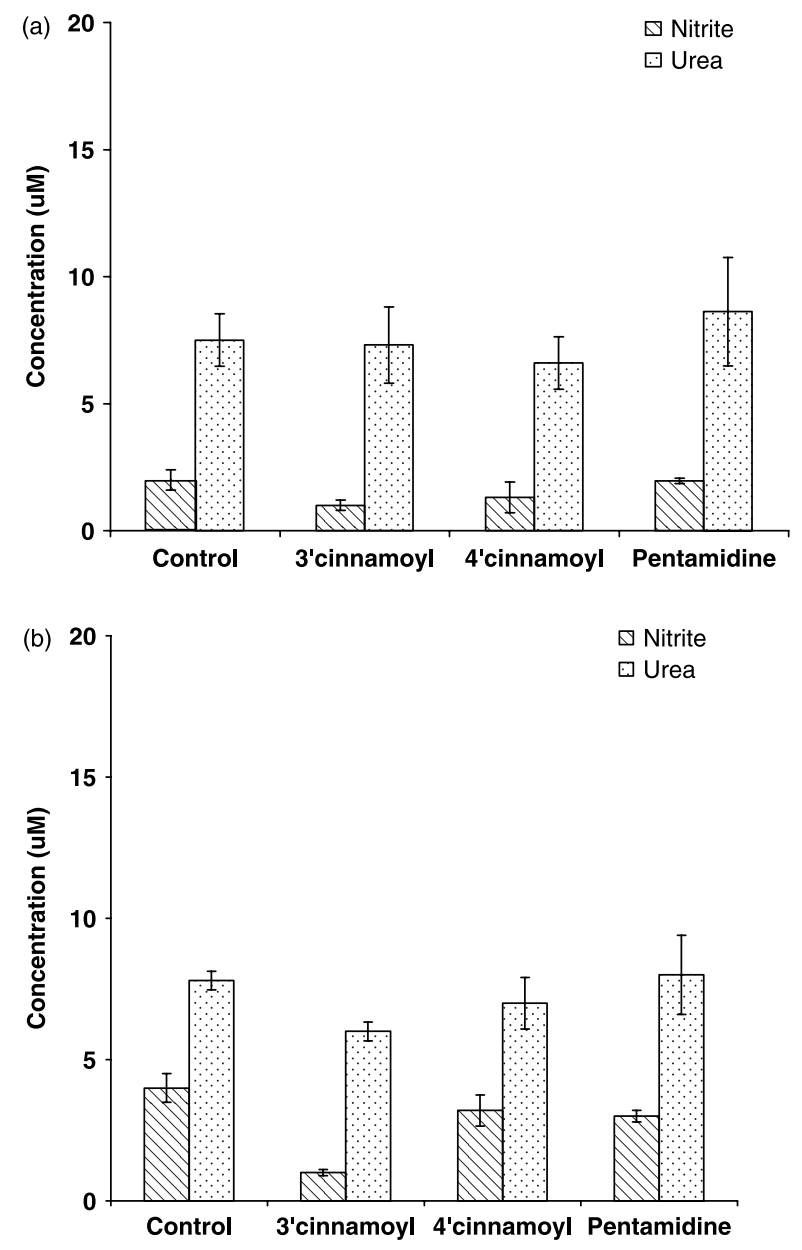

Figure 6. Arginase activity from L. amazonensis promastigotes/IP (a) and axenic amastigotes/AA (b), according to urea production, where $3^{\prime}$-methoxy cinnamoyl was able to decrease the arginase activity in amastigotes.

in Trypanosomatids was made in 1995 by Paveto and collaborators [25], in Trypanosoma cruzi. The dependence of cofactors, as well as the susceptibility of the inhibitors/activators, demonstrated the similarity of the enzyme with the one which participates in the neuronal transduction in mammals. The NOS system was also evidenced in $L$. donovani, but the biological significance, as well as the relation with the pathway existing in the macrophage (induced and harmful for these microorganisms), is still unknown [18].

Considering the importance of the cellular signaling pathways involving the host cells and parasites of the Leishmania genus, there are few studies in the literature related to the importance of the arginase and NOS activity in the parasite. In our researches of experimental chemotherapy to treat Leishmaniasis, we evaluated the effect of the more active 4-phenyl-5cinnamoyl-1,3,4-thiadiazolium-2-phenylamine chlorides $\left(3^{\prime}-\right.$ or $4 '$-methoxy) which showed a significative effect in the reduction of the NO production in promastigotes and axenic amastigotes cultures. The inhibition was evident through NADPH consumption 
by NOS purified from both evolutive forms of the parasite (that presented the cNOS form of the enzyme) [6,7]. No significant effect on the arginase activity was verified in IP, but the $3^{\prime}$-methoxy cinnamoyl compound was able to inhibit this enzyme activity.

Many mesoionic derivatives possess useful biological activity $[12,13,26,27]$. The structural characteristics of mesoionic compounds, which contain distinct regions of positive and negative charges associated with a poly-heteroatomic system, enable them to cross cellular membranes and interact strongly with biomolecules. Other mesoionic compounds (sydnones, sydnonimines and oxatriazol) are, in vivo, NO donors, therefore possessing oxygen instead of sulphur as the heteroatomic system of the mesoionic ring $[14,28]$. In contrast, the thiadiazolium compounds used in this work are not NO donors. This characteristic increases the positive charge on the mesoionic ring and allows extensive conjugation of the side-chain with the exocyclic moiety. This seems to be important for the quantification of the anti-Leishmania activity in these compounds. Furthermore, the recognition sites on NOS, arginase and axenic amastigotes provide multiple ways for the regulation of the NO and polyamines levels as well as the crosstalk between second messenger systems, making, this hypothesis worthy to be investigated in Leishmania sp.

\section{References}

[1] Vincendeau P, Gobert AP, Daulouede S, Moynet D, Mossalayi MD. Arginases in parasitic diseases. Trends Parasitol 2003; 19:9-12.

[2] Peluffo G, Piacenza L, Irigoin F, Alvarez MN, Radi R. L-arginine metabolism during interaction of Trypanosoma cruzi with host cells. Trends Parasitol 2004;8:363-369.

[3] Geigel LF, Leon LL. Cyclic 3'-5' guanosine monophosphatedependent activity in Leishmania amazonensis. Mem Inst Oswaldo Cruz 2003;4:499-500.

[4] Genestra M, Cysne-Finkelstein L, Leon LL. Comparative analysis of nitric oxide production by Leishmania sp. Med Microbiol Immunol 2003;4:217-223.

[5] Genestra M, Cysne-Finkelstein L, Leon LL. Effect of L-arginine analogs and a calcium chelator on nitric oxide (NO) production by Leishmania sp. J Enzyme Inhib Med Chem 2003;5:445-452.

[6] Genestra M, Souza WJ, Guedes-Silva D, Machado GM, Cysne-Finkelstein L, Bezerra RJ, Monteiro F, Leon LL. Nitric oxide biosynthesis by Leishmania amazonensis promastigotes containing a high percentage of metacyclic forms. Arch Microbiol 2006;185(5):348-354.

[7] Genestra M, Guedes-Silva D, Souza WJ, Cysne-Finkelstein L, Soares-Bezerra RJ, Monteiro FP, Leon LL. Nitric oxide synthase (NOS) characterization in Leishmania amazonensis axenic amastigotes. Arch Med Res 2006;37(3):328-333.

[8] Genestra M, Cysne-Finkelstein L, Vignólio-Alves L, Leon LL. Effect of amidine derivatives on nitric oxide production by Leishmania amazonensis promastigotes and axenic amastigotes. Nitric Oxide: Biol Chem 2003c;8:1-6.

[9] Kanyo ZF, Scolnick LR, Ash DE, Christianson DW. Structure of a unique binuclear manganese cluster in arginase. Nature 1996;383:554-557.
[10] da Silva ER, Castilho TM, Pioker FC, Tomich de Paula Silva $\mathrm{CH}$, Floeter-Winter LM. Genomic organisation and transcription characterisation of the gene encoding Leishmania (Leishmania) amazonensis arginase and its protein structure prediction. Int J Parasitol 2002;32(6):727-737.

[11] Soares-Bezerra RJ, Leon LL, Genestra M. Recent advances on leishmaniasis chemotherapy: Intracelular molecules as a drug target. Braz J Pharm Sci 2004;40:139-149.

[12] Senff-Ribeiro A, Echevarria A, Silva EF, Veiga S, Oliveira MB. Effect of a new 1,3,4-thiadiazolium mesoionic compound (MI-D) on B16-F10 murine melanoma. Melanoma Res 2003; 5:465-471.

[13] Lima EO, Maia RF, Filho JMB, Filho LX. Atividades antibacteriana e antifúngica de derivados mesoiônicos. Rev Microbiol 1986;17:132-136.

[14] Kier LB, Roche EB. Medicinal chemistry of the mesoionic compounds. J Pharm Sci 1967;56(2):149-168.

[15] Cysne-Filkelstein L, Aguiar-Alves F, Temporal RM, Leon LL. Leishmania amazonensis: Long-term cultivation of axenic amastigotes is associated to metacyclogenesis of promastigotas. Exp Parasitol 1998;89:58-62.

[16] Silva EF, Canto-Cavalheiro MM, Braz VR, Cysne-Finkelstein L, Leon LL, Eschevarria A. Synthesis, and biological evaluation of new 1,3,4-thiadiazolium-2-phenylamine derivatives against Leishmania amazonensis promastigotes and amastigotes. Eur J Med Chem 2002;12:979-984.

[17] Green LC, Wagner DA, Glogowski J, Skipper Pl, Wishnok JS, Tannenbaum SR. Analysis of nitrate, nitrite and $\left({ }^{15} \mathrm{~N}\right)$ nitrate in biological fluids. Analyt Biochem 1984;36:126-131.

[18] Basu NK, Kole L, Ghosh AI, Das PK. Isolation of a nitric oxide synthase from protozoam parasite, Leishmania donovani. FEMS Microbiol Lett 1997;156:43-47.

[19] Hiki K, Hattori R, Kawai C, Yui Y. Purification of insoluble nitric oxide synthase from rat cerebellum. J Biochem 1992; 111:556-558.

[20] Chen Y, Rosazza JPN. A bacterial nitric oxide synthase from a Nocardia species. Biochem Biophys Res Commun 1994;203: 1251-1258.

[21] Corraliza IM, Campo ML, Soler G, Modolell MJ. Determination of arginase activity in macrophages: A micromethod. Immunol Methods 1994;174:231-235.

[22] Corraliza IM, Soler G, Eichmann K, Modolell M. Arginase induction by suppressors of nitric oxide synthesis (IL-4, IL-10 and PGE2) in murine bone-marrow-derived macrophages. Biochem Biophys Res Commun 1995;206:667-673.

[23] Schmidt HH, Gagne GD, Nakane M, Pollock JS, Miller MF, Murad F. Mapping of neural nitric oxide synthase in the rat suggests frequent co-localization with NADPH diaphorase but not with soluble guanylyl cyclase, and novel paraneural function for nitrinergic signal transduction. J Histochem Cytochem 1992;40:1439-1456.

[24] Johanson KU, Carbeg M. NO-synthase: What can research on invertebrates add to what is already know? Adv Neuroimmunol 1995;5:431-442.

[25] Paveto C, Pereira C, Espinosa J, Montagna AE, Farber M, Esteva M, Flawia MM, Torres HN. The nitric oxide transduction pathway in Trypanosoma cruzi. J Biol Chem 1995;28:16576-16579.

[26] Senff-Ribeiro A, Echevarria A, Silva EF, Veiga S, Oliveira MB. Antimelanoma activity of 1,3,4-thiadiazolium mesoionics: A structure-activity relationship study. Anticancer Drugs 2004;3:269-275.

[27] Kosonen O, Kankaanranta H, Malo-Ranta U, Moilanen E. Nitric oxide-releasing compounds inhibit neutrophil adhesion to endothelial cells. Eur J Pharmacol 1999;2:111-117.

[28] Schonafinger K. Heterocyclic NO prodrugs. Farmaco 1999; 54(5):316-320. 